\title{
Impacts of temperature, relative humidity and total number of fruits on cucurbit fruit fly infestations under field condition
}

\author{
MM Rahman, T Sultana, MM Uddin, M Shahjahan
}

\author{
Department of Entomology, Bangladesh Agricultural University, Mymensingh-2202, Bangladesh
}

\begin{abstract}
The research was carried out in the field laboratory of the Department of Entomology, Bangladesh Agricultural University during April to July 2013 to correlate the temperature, relative humidity and number of fruits with the level of fruit infestations by cucurbit fruit fly, Bactrocerea cucubitae. Three cucurbitaceous vegetables namely bitter gourd (BARI Karola-1), ridge gourd (BARI Jhinga-1), and snake gourd (Local Chichinga) were taken as host crops. Percent fruit infestations were compared with the natural variation of temperature, relative humidity and number of fruits under field condition. Fruit infestations varied significantly with the variation of temperature, relative humidity and total number of fruits among three selected vegetables. Increasing of temperature had profound positive role in bitter gourd fruit infestation whereas negative relationship was found for ridge gourd infestation. However, statistically insignificant but positive effect of temperature was observed in snake gourd infestation. Fruit infestation of ridge gourd and snake gourd increased with the increase of relative humidity while negative relationship was observed in case of bitter gourd. Percent fruit infestations by cucurbit fruit fly were also found to be affected by total number of fruits. Positive but weak relationships were found between percent fruit infestations and total number of fruits of all three vegetables used in the experiments.
\end{abstract}

Key words: Bitter gourd, ridge gourd, snake gourd, cucurbit fruit fly

Progressive Agriculturists. All rights reserved.

*Corresponding Author: mahirbau@yahoo.com

\section{Introduction}

The cucurbitaceous crops form one of the largest groups in the vegetable kingdom with their wide adaptation from arid to the humid tropic environments. It is also known as gourd family or melon family comprising about 118 genera and 825 species (Jeffrey, 1990). The cucurbits such as cucumber, bitter gourd, sponge gourd, ridge gourd, bottle gourd, sweet gourd, snake gourd, ash gourd, pointed gourd, and pumpkins are some of the major vegetables grown across Bangladesh. Cucurbits are cultivated in both summer and winter seasons. During the summer season, it becomes principal vegetables mostly covering the market due to the scarcity of other vegetables specially winter vegetables. The major constraint to sustainable increased productivity of cucurbits is the high incidence of insect pests. Cucurbits are infested by a number of pests such as cucurbit fruit fly, red pumpkin beetle, epilachna beetle etc. Among them cucurbit fruit fly, Bactrocera cucurbitae (Coquillett) is a devastating pest of different cucurbit vegetables in many parts of the world which may cause more than 60\% yield loss (Kapoor, 1993). The pest has been reported to damage 81 host plants and as a major pest of cucurbitaceous vegetables, especially the bitter gourd, musk melon, snap melon, and snake gourd, ridge gourd (Anonymous, 2004). The female adults lay eggs inside the fruits with their sharp ovipositor. Afterward, fruit juice oozes out which transforms into resinous brown deposit. The eggs hatch inside the fruit into maggots (worms) which feed on the flesh (pulp) of the fruit and make tunnels 


\section{Cucurbit fruit fly infestations under field condition}

in fruits. The infested fruits become rotten, dry up and finally shed up prematurely. If not rotted, become deformed and market value reduce severely. Severity and extent of damage is dependent on the climatic parameters such as temperature, relative humidity as well as host preference. Moreover, host preference is influenced by various plant characters. Depending on the environmental conditions and susceptibility of the crop species, the extent of losses varies between 30 to 100\% (Gupta and Verma, 1992, Dhillon et al., 2005a, b, c and Shooker et al., 2006). Therefore, it is important to identify the effect of climatic parameters and host preference parameter for the sustainable management of cucurbit fruit fly. Considering the aforesaid issues the present study was conducted to find out the role of temperature, humidity and total number of fruit on fruit infestation by cucurbit fruit fly.

\section{Materials and Methods}

The experiments to correlate the temperature, relative humidity and number of fruits to the level of fruit infestations by cucurbit fruit fly (Bactrocera cucurbitae) were carried out in the field laboratory of Department of Entomology, Bangladesh Agricultural University during the period from April to July 2013. To raise the seedlings and plants the land was ploughed and cross-ploughed for several times with a power tiller to obtain good tilth. All ploughing operations were followed by breaking up the clods. All weeds and stubbles were removed from the field and finally, the unit plots were prepared as $10 \mathrm{~cm}$ raised beds along with basal doses of recommended fertilizers. Total 9 plots with 1 pit in each were made for experiments. The size of the each plot was 4 feet by 6 feet. Quality seeds of three selected cucurbitaceous vegetables such as bitter gourd (BARI Karola-1), ridge gourd (BARI Jhinga-1) and snake gourd (Local Chichinga) were collected from Bangladesh Agricultural Research Institute (BARI), Gazipur and from the local market of Mymensingh town. Seeds were soaked overnight for proper germination and sown in pits with three replications of each. Three seeds were sown in each pit and seedlings were thinned out leaving one healthy seedling per pit after 7 days of germination. Bamboo platform (macha) was made as a means of propping, allowing easy creeping and preventing the plant from lodging. All suitable horticultural practices were done for proper growth and development of the plants. Data on total fruits and infested fruits were collected at 5 days intervals started at 10 days after first flowering. The percentage of infested fruit was calculated by using the following formula:

$\%$ fruit infestation $=\frac{\text { Number of infested fruit }(\mathrm{IF})}{\text { Number of total fruit }(\mathrm{TF})} \times 100$

Data on weather parameters (temperature and relative humidity) were collected from the field using digital thermometer and hygrometer during the study periods. Effect of temperature and relative humidity were determined by comparing with percent fruit infestations for three selected vegetables. Likewise, the impact of total number of fruits on the percent fruit infestations by cucurbit fruit fly were also analyzed statistically. Data were analyzed by MSTAT-C, Microsoft excel worksheet.

\section{Results and Discussion}

\section{Role of temperature on percent fruit infestations}

Data on percent fruit infestations were correlated with natural temperature and their linear relationship was observed for three different cucurbitaceous vegetables under filed conditions. Temperature varied from $28.1^{0} \mathrm{C}$ to $31.3^{0} \mathrm{C}$ during experimental period. Positive linear relationship was found between percent bitter gourd infestation and temperature (Fig. 1). According to the graph (Fig.1), there was a moderate positive relationship $\left(\mathrm{R}^{2}=0.786\right)$ between the temperature and percent fruit infestation where one unit increase of temperature would lead to increase $1.521 \%$ fruit infestation. Therefore, it could be concluded that significant positive relationship was present between temperature and percentage of bitter gourd fruit infestation. The present result agreed with previous findings of Krishna et al. (2006), they stated that increase of temperature had effect on fruit fly infestation.

On the other hand, negative relationship was found between temperature and percent ridge gourd infestation (Fig. 2). Based on the graph it was confirmed that, rising of one unit temperature would cause $1.686 \%$ decrease in fruit infestation. The 
present result is agreed by Gaine et al. (2013), they conducted a survey at weekly intervals on different cucurbit crops such as bottle gourd, cucumber, ridge gourd, and bitter gourd. They reported that maximum temperature was not significantly correlated with infestation and the population of fruit fly but minimum temperature was significantly and negatively correlated with the infestation and population of fruit flies.

However, there was no significant relationship $\left(\mathrm{R}^{2}=\right.$ 0.000 ) between temperature and percentage of fruit infestation in snake gourd (Fig.3). The graph shows that rising of one unit of temperature can raise $0.017 \%$ fruit infestation only. This result was contradictory with Butanni and Jotwani (1984) because they stated fruit fly populations and infestations were in general positively correlated with temperature. This variation may be for the variation of seasonal and geographical distribution.

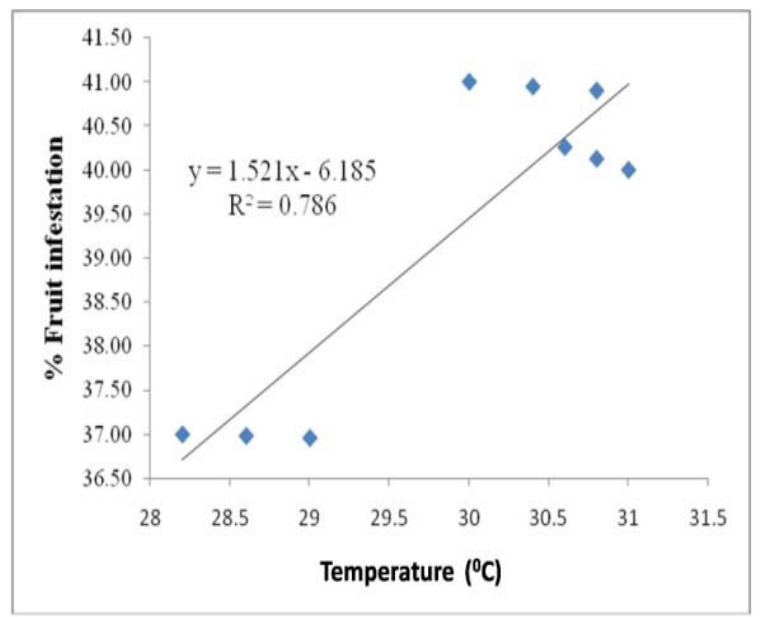

Figure 1. Role of temperature on percentage fruit infestation in bitter gourd

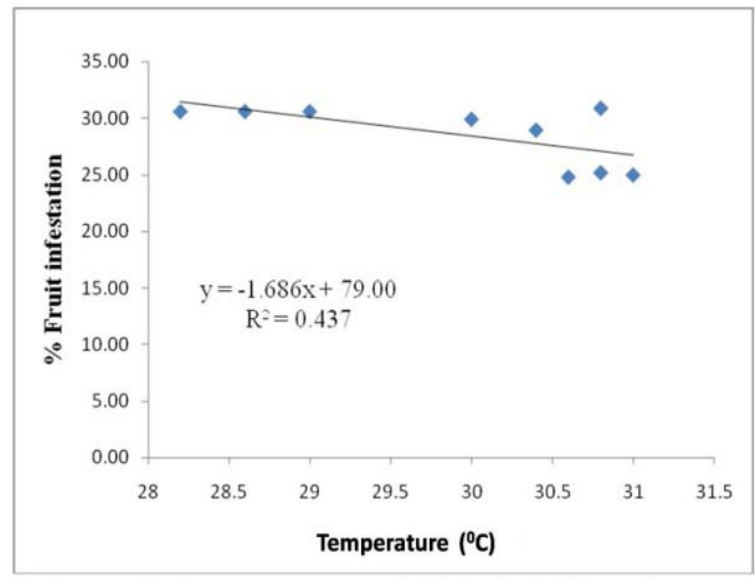

Figure 2. Role of temperature on percent fruit infestation in ridge gourd

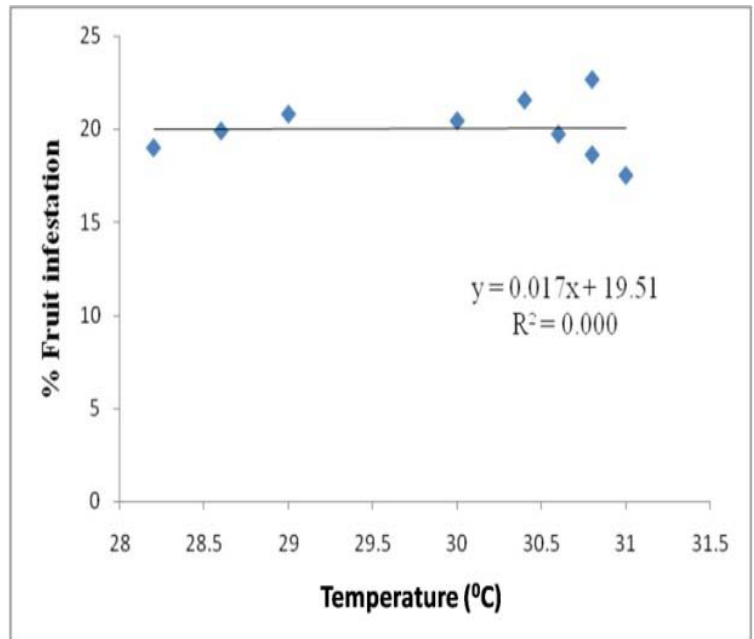

Figure 3. Role of temperature on percent fruit infestation in snake gourd

Therefore, fruit infestation in bitter gourd had positive relationship and ridge gourd had negative relationship with the temperature at natural field condition whereas, snake gourd fruit infestation had no strong relationship with the temperature.

\section{Role of relative humidity on percent fruit infestation}

Data on fruit infestations and percent relative humidity were analyzed statistically to find out the relationship between them. Relative humidity varied from $78 \%$ to $92 \%$ during conducting experiment. Negative relationship between percent relative humidity and percentage of fruit infestation was found in bitter gourd (Fig. 4). According to the data, the relationship was moderately negative where one unit increase of relative humidity reduced $0.248 \%$ fruit infestation. The present result is closely supported by Krishna et al. (2006), they reported that maximum and minimum relative humidity had effect of fruit fly infestation and trapping in bitter gourd, ridge gourd and cucumber.

On the other hand, positive relationship between percent fruit infestation and percent relative humidity was found for ridge gourd and snake gourd (Fig. 5 and Fig. 6 respectively). The increase of one percent relative humidity raised $0.499 \%$ and $0.137 \%$ fruit infestations for ridge gourd and snake gourd respectively.

Therefore, increase of relative humidity had profound effect in raising fruit infestation of ridge 


\section{Cucurbit fruit fly infestations under field condition}

gourd and snake gourd but reduce bitter gourd fruit infestation under the natural condition.

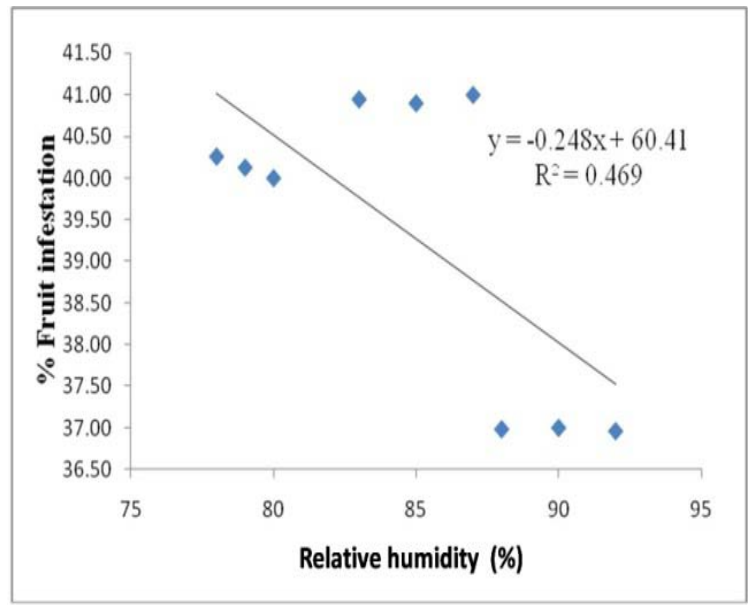

Figure 4. Role of relative humidity on percent fruit infestation in bitter gourd

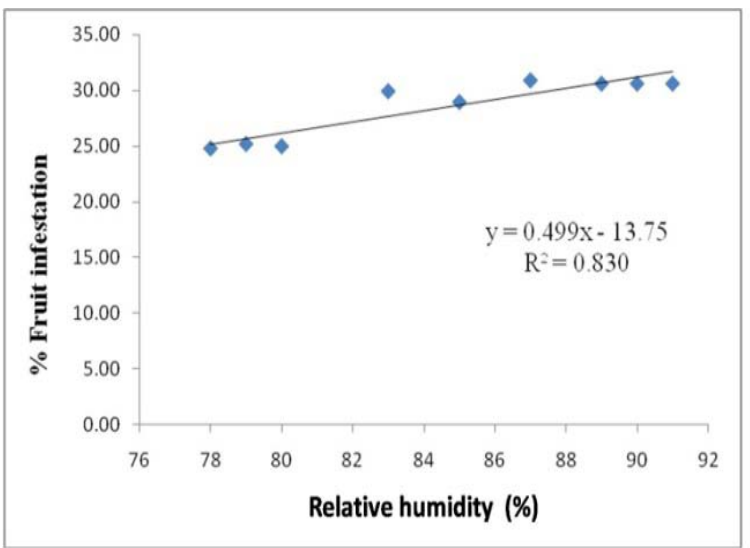

Figure 5. Role of humidity on percent fruit infestation in ridge gourd

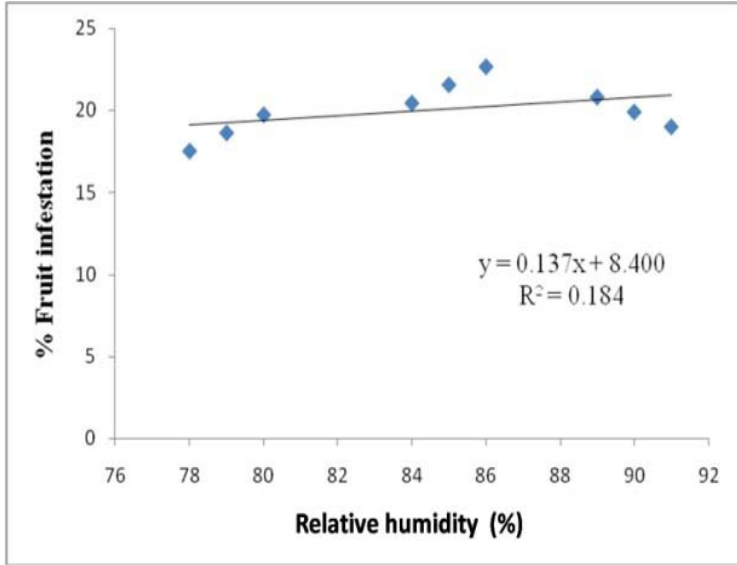

Figure 6. Role of relative humidity on percent fruit infestation in snake gourd

\section{Relationship between fruit infestation and total number of fruits}

Percent fruit infestations by cucurbit fruit fly were analyzed statistically against total number of fruits to find out the relationship between them. Total number of fruits was 12 to 38 and diversified for different vegetables during the study periods. For all three selected vegetables, percent fruit infestations significantly varied with the variation of total number of fruits. The present results showed positive but weak relationship $\left(R^{2}=0.03\right.$ to 0.1$)$ between total number of fruits and percentage of fruit infestations in bitter gourd, ridge gourd and snake gourd (Fig. 79).

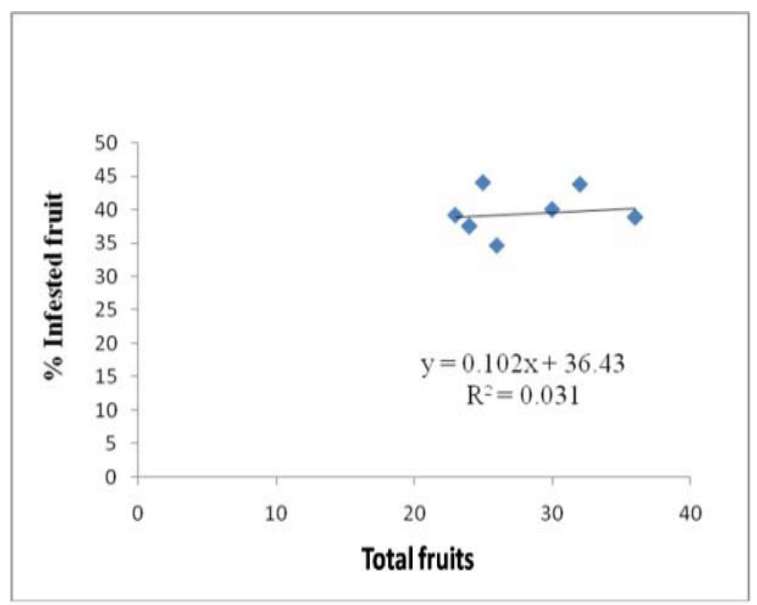

Figure 7. Role of total fruit on percent infested fruit in bitter gourd

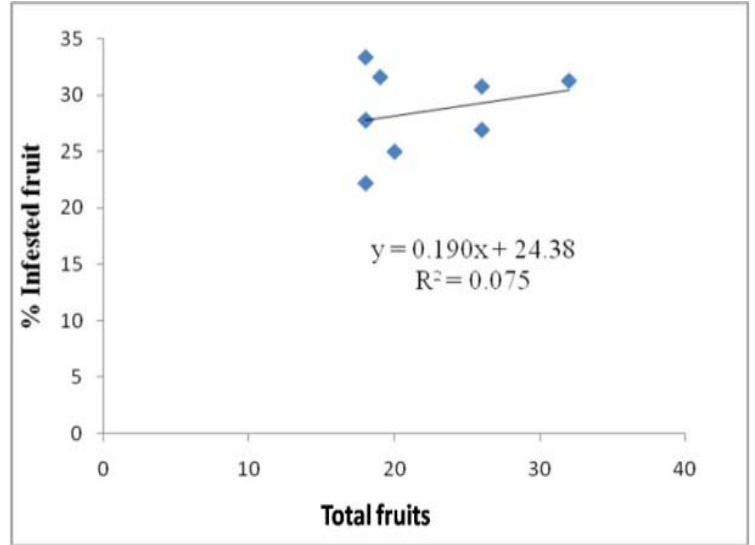

Figure 8. Role of total fruits on percent fruit infestation in ridge gourd

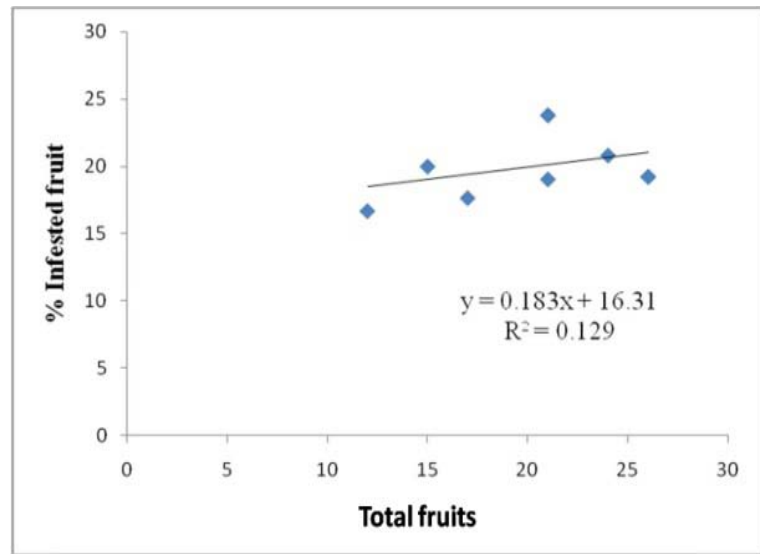

Figure 9. Role of total fruits on percent fruit infestation in snake gourd 
According to the data, $0.102 \%, 0.19 \%$ and $0.183 \%$ more fruit infestations were found in bitter gourd (Fig. 7), ridge gourd (Fig. 8) and snake gourd (Fig. 9) respectively with the increase of one fruit.Therefore, there was positive relationship between the number of fruits and percent fruit infestations by cucurbit fruit fly under field conditions.

\section{References}

Anonymous (2004). Integrated management of cucurbit fruit fly, Bactrocera cucurbitae (Coquillett) in Bangladesh. IPM CRSP Bangladesh site technical bulletin no. 1.

Butanni DK, Jotwani MG (1984).Insects in Vegetables. Periodical Expert Book Agency. Vivek-Vihar, Delhi, India.pp . 6979.

Dhillon MK, Naresh JS, Ram S, Sharma NK (2005b) Influence of physico-chemical traits of bitter gourd, Momordica charantia L. on larval density and resistance to melon fruit fly, Bactrocera cucurbitae (Coquillett). J. Appl. Entomol. 129: 393-399.

Dhillon MK, Naresh JS, Singh R, Sharma NK (2005a) Evaluation of bitter gourd (Momordica charantia L.) genotypes for resistance to melon fruit fly, Bactrocera cucurbitae. Indian J. Pl. Prot. 33(1): 55-59.

Dhillon MK, Singh R, Naresh JS, Sharma HC (2005c) The melon fruit fly, Bactrocera cucurbitae: A review of its biology and management. J. Insect Sci. 16pp.

Gaine SA, Khan ZH, Ahangar RA, Bhat HA, Hussain B (2013). Population dynamics, distribution, and species diversity of fruit flies on cucurbits in Kashmir Valley, India. The J. Insect Sci. 13: 65.

Gupta D, Verma AK (1992). Population fluctuations of the maggots of fruit flies Dacus cucurbitae (Coquillett) and D. tau (Walker) infesting cucurbitaceous crops. Adv. Pl. Sci. 5: 518523.

Jeffrey C (1990). Systematics of the Cucurbitaceae: an overview. In: Bates, D.M., Robinson, R.W. and Jeffrey. C. (eds) Biology and Utilization of the Cucurbitaceae. Cornell University Press, Ithaca, New York, pp.3-9.

Kapoor VC (1993). Indian Fruit Flies. Oxford \& IBH Publishing Co. Ltd. New Delhi, India. pp. 228.

Krishna KNK, Abraham V, Shivakumara B, Krishnamoorthy PN, Ranganath HR (2006). Relative incidence of Bactrocera cucurbitae (Coquillett) and Dacus ciliatus on cucurbitaceous vegetables. Fruit Flies of Economic Importance: From Basic to Applied Knowledge Proceedings of the $7^{\text {th }}$ International Symposium on Fruit Flies of Economic Importance, Salvador, Brazil. pp. 249-253.

Shooker P, Khayrattee F, Permalloo S (2006). Use of maize as a trap crops for the control of melon fly, B. cucurbitae (Diptera : Tephritidae) with GF-120. Bio-control and other control methods (Online). Availible on http//www.fcla.edu /FlaEnt/fe87. 354 p.pdf. (Retrieved on: 20th Jan.2008). 